\title{
Value Meaning Not Provided
}

National Cancer Institute

\section{Source}

National Cancer Institute. Value Meaning Not Provided. NCI Thesaurus. Code C62635.

This Value Meaning was not provided and is to be manually entered. 